\title{
Collection and Processing of Food-Borne Animal by-Products
}

\author{
Labioui Hicham ${ }^{1}$, Jamila Cherkaoui ${ }^{2}$, Zineb Guessous ${ }^{1}$, Abderrahim Benzakour ${ }^{1}$, \\ Mohammed Sobh ${ }^{2}$
}

${ }^{1}$ Department of Biology, Faculty of Sciences, Ibn Tofail University, Kenitra, Morocco

${ }^{2}$ Department of Biology, Ain Chok Faculty, Hassan II University, Casablanca, Morocco

Email address:

labioui_h@yahoo.fr (L. Hicham)

\section{To cite this article:}

Labioui Hicham, Jamila Cherkaoui, Zineb Guessous, Abderrahim Benzakour, Mohammed Sobh. Collection and Processing of Food-Borne Animal by-Products. Frontiers in Environmental Microbiology. Vol. 4, No. 1, 2018, pp. 22-28. doi: 10.11648/j.fem.20180401.14

Received: December 23, 2017; Accepted: February 6, 2018; Published: March 8, 2018

\begin{abstract}
The meat sector consists mainly of large structures generating substantial volumes. It is worth pointing out that many of the companies belong to large groups with subsidiaries specialized in the processing and valorisation of by-products. The turkey waste generates health problems in the same way as other hazardous wastes. To remedy this, successful biological transformation work has been developed. Experiments were carried out on the use of modified ferments. At this level, we isolated and characterized strains of lactic acid bacteria, they are labeled RANBL2, RANBL10 and have an important acidifying and fermentation power, these strains were inoculated in mixed culture with two yeast strains referenced (BWL7, BWL9) which are characterized by a strong enzymatic activity of order 2842 and $1787 \mu$ mol. L-1.min-1. In addition, the acidity increased from $0.17 \%$ to $1.33 \%$ between the beginning and the end of fermentation. The pH became stable (3.97) on the twelfth day of fermentation. It follows that the combined action of all the factors ( $\mathrm{pH}$, acidity, bacteriocin, etc.) in the same fermentation must is responsible for the positive evolution of the hygienic quality of the fermentation product.
\end{abstract}

Keywords: Turkey Wastes, Microbial Strains, Fermentation, Valorisation

\section{Introduction}

The evaluation of the poultry by-product and animal waste deposit must take into account the regulatory framework, highly impregnated in this sector, as well as the market data. The management of poultry by-products resulting from the processing of animal products is governed by strict regulations set up following the Bovine Spongiform Encephalopathy crisis.

This regulation is based on Regulation (EC) No 1069/2009, complemented by Regulations (EC) No $142 / 2011$. It lays down the health rules for animal byproducts not intended for human consumption. The Help tool for recovery of by-products in animal feed and agriculture is a good tool to have a clear approach to this framework and inherent requirements. In recent years the meat slaughtering industry has expanded enormously around the world. All the conditions are met to carry out this industry which does not cease to develop. This sector is very polluting and generates a large amount of harmful waste. This waste from slaughterhouses is a potential source of valuable biomass. This waste is rich in organic matter and fiber, and its transformation for recycling is a feasible means [3].

The techniques and appropriate biotechnological processes for the metabolism and the recovery of such wastes are to improve the field of animal feed or soil fertilization, and which respects the environment better, undoubtedly explains the importance of biotechnology as a tool Biotransformation of slaughterhouse waste. The chemical and microbiological composition of waste from slaughterhouses in red meat is of particular importance for researchers in the field of byproduct recycling and organic waste [7].

These wastes can not be used directly or in their raw state because of their microflora which is dangerous both from an alteration point of view and from a hygienic point of view. The biological treatment of these wastes rests on the ability of microorganisms to transform certain compounds considered as substrates into upgraded products. After the success of these types of biological transformation 
techniques through anaerobic fermentation, our study is based on the use of bacterial microorganisms capable of converting waste slaughterhouses as a stable end products will be intended for animal feed, Or for the fertilization of the soil [2].

\section{Materials \& Methods}

\subsection{Raw Material}

\subsubsection{Waste Collection}

The turkey waste was collected at a rate of about $20 \mathrm{~kg} /$ experimental test, and transported to the laboratory for physico-chemical and microbiological analyzes follows a biological treatment.

\subsubsection{Preparation of Inoculum}

The isolation and purification of lactic acid bacteria strains and yeasts from different habitats were carried out on MRS medium (Man, Rogosa and Sharpe) and the solid PDA medium (Potato Dextrose Agar) solid. For the selection of the most powerful strains we based on two main criteria: acidifying power and fermentation.

\subsection{Test Experimental: Fermentation in Barrels Closed}

After draining the waste, the biotransformation of wastemolasses mixture $(20 \%)$ was carried out in closed barrels. Each barrel was filled with $20 \mathrm{~kg}$ of mixture and inoculated by the most efficient strains in order to leave a headspace to facilitate the agitation of the contents of the barrels and to prevent any overflow due to the rise of the product following production Exclusive of gas during fermentation.

\subsection{Follow-up of Fermentation}

The fermentation process during of biotransformation the slaughterhouse waste mixed with adequate proportions of molasses as a carbon source was carried out using $\mathrm{pH}$ and acidity measurements to optimize the flow of Fermentation, as well as the competence of strains used for the biotransformation of wastes thanks to their strong acidifying and antibacterial power.

\section{4. $\mathrm{pH}$ and Acidity Control}

\subsection{1. $\mathrm{pH}$}

The $\mathrm{pH}$ measurement is carried out using a micro-pH combined electrode electronic pH-refining meter. The apparatus is previously calibrated with an acidic and alkaline solution at known pH. $5 \mathrm{~g}$ of sample are homogenized in 20 $\mathrm{ml}$ of distilled water, the mixture is filtered. The $\mathrm{pH}$ meter electrode is immersed in the filtrate and the value is indicated on the electronic refinement.

\subsubsection{Titratable Acidity}

For the acidity, $5 \mathrm{~g}$ of fresh sample are taken, to which 20 $\mathrm{ml}$ of distilled water are added, the mixture is thoroughly mixed and filtered on $9 \mathrm{~mm}$ diameter Whatman filter paper. Phenophthalein is used as a color indicator. A solution of
$0.1 \mathrm{~N} \mathrm{NaOH}$ is then added.

\subsection{Microbiological Analyzes During Fermentation of Waste}

These analyzes allow one hand the microbial characterization of these wastes and other hand keep track of the different microbial populations during the fermentation of waste from slaughterhouses.

\subsubsection{Preparation of Dilutions}

For a period of 3 weeks, the sample is taken for analysis in a $10 \mathrm{~g}$ Erlenmeyer flask containing $90 \mathrm{ml}$ of sterile saline. A 10-1 stock dilution is thus obtained, from which decimal dilutions up to 10-7 are carried out.

\subsubsection{Flores Enumerated}

- Total aerobic mesophilic flora (FMAT): this flora is a good indicator of the overall contamination of fermented waste. It is counted on the PCA agar incubated for 24 hours at $30^{\circ} \mathrm{C}$.

- Coliforms: on deoxycolate lactose (DCL) agar incubated for $24 \mathrm{~h}$ at $30^{\circ} \mathrm{C}$ for total coliforms and at $44^{\circ} \mathrm{C}$ for fecal coliforms.

-Fecal streptococci: enumeration on sodium azide incubated at $37^{\circ} \mathrm{C}$ for 48 hours.

-Staphylococci: are counted on Baird Parker agar supplemented with egg yolk and potassium tellurite and incubated at $37^{\circ} \mathrm{C}$ for $48 \mathrm{~h}$.

-Yeasts and molds: are counted on the Sabouraud 4\% glucose medium incubated for 5 days at $22^{\circ} \mathrm{C}$.

-Lactic bacteria: they are counted on the agar of MRS medium and incubated for $48 \mathrm{~h}$ at $30^{\circ} \mathrm{C}$.

-Salmonellae: a pre-enrichment in the medium of serinecystine, followed by enrichment on the tetrathionate broths, incubated at $37^{\circ} \mathrm{C}$. for 24 hours. The enumeration was carried out simultaneously on the SS media incubated at $30^{\circ}$ for 24 h.

-Clostridiums sulfito-reducer: this is used for this enumeration Reiforced Clostridium Agar culture medium in tubes to favor the anaerobic conditions, with a heat treatment of $80^{\circ} \mathrm{C}$ for $10 \mathrm{~min}$ to activate clostridial spores. The tubes are incubated at $37^{\circ} \mathrm{C}$. for 48 hours only the black colonies are counted.

\subsection{Physicochemical Analyzes}

\subsubsection{Total Nitrogen}

The total nitrogen is mineralized by the action of sulfuric acid. The ammonia obtained is displaced by means of a concentrated solution of sodium hydroxide and then collected in a buffer solution of boric acid and titrated with a hydrochloric solution in the presence of a colored indicator.

\subsubsection{Dosage of Potassium}

In the case of potassium, the reciprocal influence of the alkali metals is corrected by the addition of cesium to the sample.

A Cs $0.1 \%$ solution ( $1.26 \mathrm{~g}$ of $\mathrm{Cs}$ in 1 liter of $\mathrm{H} 2 \mathrm{O})$ is 
prepared. A calibration range is then carried out using a solution of $100 \mu \mathrm{l} / \mathrm{ml}$ in cesium $0.1 \%$.

\subsubsection{Determination of Phosphorus}

The determination of the phosphorus is carried out by spectrophotometry (AFNOR V18-106).

\subsubsection{Organic Material}

The determination of the organic matter content was carried out using a continuous flow analyzer (TECHNICOM) at the wavelength of $627 \mathrm{~nm}$.

\subsubsection{Dry Matter}

The determination of the non-volatile solids content is determined by baking $105^{\circ} \mathrm{C}$. of an exactly weighed mass of the fresh sample. A quantity of $30 \mathrm{~g}$ of fresh sample is weighed into a previously dried and tared box. After a night of baking in an oven set) $105^{\circ} \mathrm{C}$, , the box plus the dried sample are weighed after cooling in a desiccator.

\subsubsection{Ashes}

The ashes are determined by calcining an exactly weighed mass of the fresh sample to be analyzed until the constant weight is obtained. A quantity of $20 \mathrm{~g}$ is precisely weighed in a clean crucible previously dried and tared. The crucible is placed at a temperature reached progressively $550^{\circ} \mathrm{C}$. The calcination lasts 24 to 30 hours until a white residue (constant weight) is obtained, at the end the crucible is weighed after total cooling in the desiccator.

\section{Results \& Discussions}

\subsection{Isolation and Characterization of Lactic Strains on MRS Medium}

The lactic bacteria form a very interesting group of microorganisms, which is characterized by the ability to ferment carbohydrates into lactic acid, favorable for the preservation of food.

The strains of lactic acid bacteria are isolated from different biotopes, namely milk, press juice and mixed sugar cane juice. Only gram positive and negative catalase bacteria were retained and striated on solid MRS (Man, Rogosa, Sharpe) medium.

The results obtained show that amongst ten strains of lactic acid bacteria, only 2 strains (BLh5, BLh10) which exhibit performance characteristics, these lactic strains are retained for the biotransformation of slaughterhouse waste (Table 1).

Table 1. Characteristics of the Lactic Acid Bacteria Cultured in Liquid MRS Medium 48 h at $30^{\circ} \mathrm{C}$. in the dark.

\begin{tabular}{|c|c|c|c|c|c|c|}
\hline Biotope & Strains & Initial PH & Final pH & Catalase test & Bactericidal test & Kind \\
\hline \multirow{4}{*}{ Cow milk } & $\mathrm{RAN}_{\mathrm{BL} 1}$ & 6.55 & 4.11 & & + & undetermined \\
\hline & $\mathrm{RAN}_{\mathrm{BL} 2}$ & 6.55 & 3.97 & - & ++ & Lactobacillus sp \\
\hline & $\mathrm{RAN}_{\mathrm{BL} 3}$ & 6.55 & 4.12 & - & - & undetermined \\
\hline & $\mathrm{RAN}_{\mathrm{BL} 4}$ & 6.55 & 4,17 & - & - & undetermined \\
\hline \multirow{5}{*}{ Sugar cane press juice } & RAN $_{\text {BL5 }}$ & 6.55 & 4.02 & - & +++ & Streptococcus sp \\
\hline & RAN $_{\text {BL6 }}$ & 6.55 & 4,23 & - & - & undetermined \\
\hline & RAN $_{\text {BL8 }}$ & 6.55 & 4.10 & - & - & undetermined \\
\hline & RAN $_{\text {BL9 }}$ & 6.55 & 4,12 & - & + & undetermined \\
\hline & $\mathrm{RAN}_{\mathrm{BL} 10}$ & 6.55 & 3.95 & - & +++ & Lactococcus sp \\
\hline
\end{tabular}

\subsection{Isolation and Characterization of Yeast Strains of Different Biotopes}

The isolation of the yeasts is carried out on semi-synthetic medium. The isolated strains are purified after four successive cycles of transplanting in a liquid medium and spreading on Potato dextrose agar (PDA) medium. The pure strains are stored at $4{ }^{\circ} \mathrm{C}$. on a PDA medium agitated in tubes. A transplanting takes place every month.

The biomass of deferent cultures in liquid medium was followed by nephelometry by spectrophotometer at a wavelength of $600 \mathrm{~nm}$.

Table 2. pH, Biomass and Enzymatic Activity of 10 yeast strains grown in semi-synthetic liquid medium for three days at $30^{\circ} \mathrm{C}$. in the dark.

\begin{tabular}{|c|c|c|c|c|c|}
\hline Strains & Initial Biomass & final Biomass & initial pH & final PH & Activity $\left(\mu\right.$ mole. $\left.L^{-1} \cdot \min ^{-1}\right)$ \\
\hline BWL1 & 0.15 & 1.17 & 5.53 & 4.27 & 815 \\
\hline BWL2 & 0.17 & 0.87 & 5.53 & 4.11 & 917 \\
\hline BWL3 & 0.21 & 1.01 & 5.53 & 4.78 & 421 \\
\hline BWL4 & 0.14 & 0.67 & 5.53 & 4.27 & 897 \\
\hline BWL5 & 0.15 & 0.78 & 5.53 & 4.35 & 752 \\
\hline BWL6 & 0.11 & 0.71 & 5.53 & 4.61 & 621 \\
\hline BWL7 & 0.20 & 1.26 & 5.53 & 4.05 & 2842 \\
\hline BWL9 & 0.15 & 1.20 & 5.53 & 4.12 & 1787 \\
\hline BWL10 & 0.13 & 0.89 & 5.53 & 4.15 & 1121 \\
\hline
\end{tabular}




\section{Fermentation Control of Leaven Prepared on Molasses}

(i). Conduct of Fermentation in Pure Cultures

Based on the previous tests (acidifying, fermenting and antibacterial potency), the selected lactic strains and two BWL7 and BWL9 yeasts were grown on a medium containing molasses as a carbon source. We examined with the three strains of lactic acid bacteria selected separately and in mixed culture, the evolution of the acidity produced on molasses. The tests are carried out at $\left(30^{\circ} \mathrm{C}\right.$. $)$ and $\mathrm{pH} 6$.

Table 3 summarizes the results recorded for the $\mathrm{pH}$ and the acidity produced as a function of the fermentation time, the final $\mathrm{pH}$ and the acidity of the RANBL10 strain are respectively of the order of 3.92 and $1.07 \%$, followed by the strain RANBL2 with An acidity rate of $1.02 \%$.

During these molasses fermentation trials, the two lactic strains selected showed a significant acidification of the medium. These acidification rates are identical to those found on the MRS medium.

\section{(ii). Mixed Culture Line on Molasses}

Two trials of mixed culture fermentation on molasses, at $30^{\circ} \mathrm{C}$ and $\mathrm{pH} 6$, were carried out. Table 3 summarizes the results obtained, the $\mathrm{pH}$ decreasing gradually to a maximum value of 3.87 in the case of mixed leaven (RANBL10 -
BWL7) with an acidity rate of $1.30 \%$. On the other hand, the mixed culture test (RANBL2 - BWL7) showed a high degree of acidification, but under the results obtained with mixed leaven (RANBL10 - BWL7), it is of the order of $1.12 \%$.

The results recorded in Table 5 show that the $\mathrm{pH}$ and acidity evolved significantly, especially for the cultivation of (RANBL10-BWL9) with an acidity of $1.14 \%$ but remains above the values obtained in the case of fermentation tests Of the lactic acid bacteria mixed with the yeast strain BWL7.

The fermentation tests carried out by mixed cultures on molasses have a significant difference compared to the previous test, especially for mixed leavening (RANBL10 BWL7), which allows a better acidification of the medium as a function of the fermentation time. The strains of lactic acid bacteria used, ferment the sugars present in the molasses in the presence of the selected yeasts, consequently to their strong fermentative and saccharolytic power and allow a smooth unrolling of the molasses fermentation.

These selected lactic strains and yeasts (BWL7 - BWL9) were chosen to carry out slaughterhouse waste processing trials by an effective biological process for this type of treatment.

Table 3. Evolution of $\mathrm{pH}$ and acidity produced during molasses fermentation after 5 days of incubation.

\begin{tabular}{lllll}
\hline Ferment & initial pH & final PH & Initial acidity (\%) & Final Acidity (\%) \\
\hline $\mathrm{RAN}_{\mathrm{BL} 2}$ & 5.98 & 4.02 & 0.23 & 1.02 \\
$\mathrm{RAN}_{\mathrm{BL} 10}$ & 6.02 & 3.92 & 0.21 & 1.07 \\
$\mathrm{RAN}_{\mathrm{BL} 2}-\mathrm{BWL}_{7}$ & 5.78 & 3.98 & 0.22 & 1.12 \\
$\mathrm{RAN}_{\mathrm{BL} 10}-\mathrm{BWL}_{7}$ & 5.81 & 3.87 & 0.25 & 1.30 \\
$\mathrm{RAN}_{\mathrm{BL} 2}-\mathrm{BWL}_{9}$ & 5.88 & 4.05 & 0.18 & 0.97 \\
$\mathrm{RAN}_{\mathrm{BL} 10}-\mathrm{BWL}_{9}$ & 5.83 & 4.03 & 0.15 & 1.14 \\
\hline
\end{tabular}

\subsection{Follow-up of the Fermentation of the Inoculated Waste by a Mixed Culture (Bacterium + Yeast)}

The monitoring of fermentation during the process of biotransformation of waste from red meat slaughterhouses with molasses was carried out using $\mathrm{pH}$ and acidity measurements.

\subsubsection{PH}

The results of the $\mathrm{pH}$ and acidity evolution are given in the figures below. These results show that a natural fermentation took place in the waste-molasses mixture inoculated by a mixed culture in the presence of lactic acid bacteria and of yeast BWL7 that the $\mathrm{pH}$ of the mixture stabilized at a value of 3.97 (Figure 1).

The study of the acidity profile showed a progressive evolution to reach a value of $1.33 \%$ after 15 days of fermentation, in fact the metabolites resulting from the organic fermentation masked their odor and gave to the finished product an acid odor and Fresh (8].

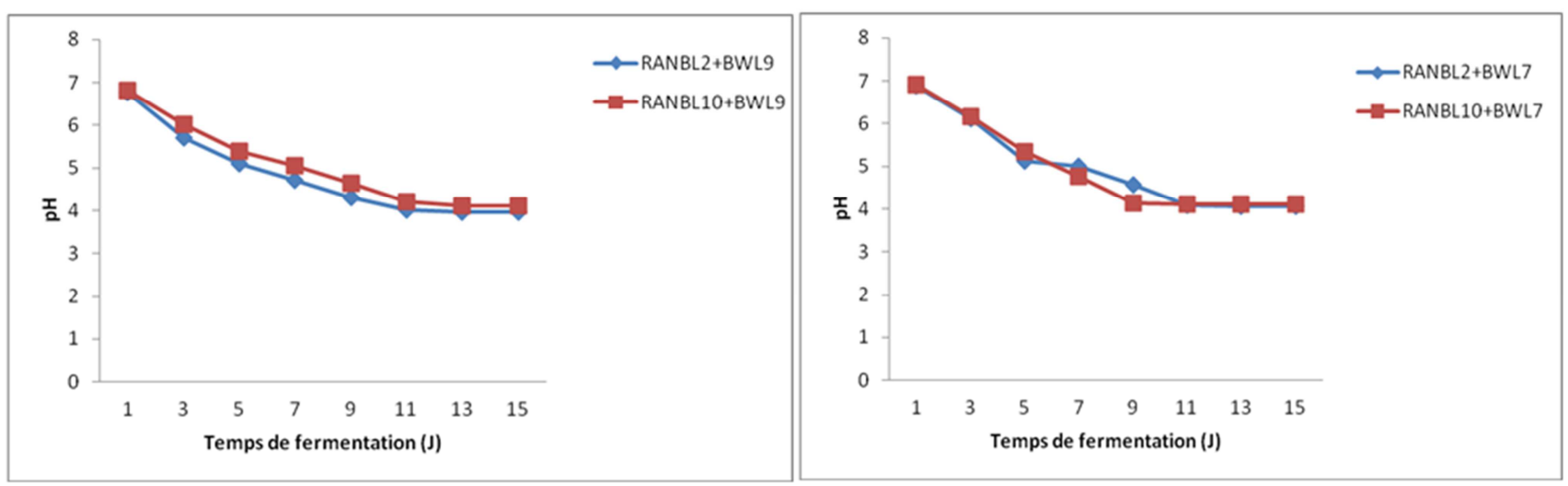

Figure 1. Evolution of the pH during the fermentation of the waste inoculated by a mixed culture. 


\subsubsection{Acidity}

The study of the profile of the acidity showed a gradual evolution to reach a value of $1.25 \%$ after 10 days of fermentation, indeed the metabolites resulting from the organic fermentation masked their odor and gave to the finished product an odor Acid and fresh [12].

The fermentation tests, with the lactic acid bacteria, were carried out under the conditions of ambient temperature and at a $\mathrm{pH}$ of 6.2. After adding the inoculum of the mixed culture, the acidity is gradually decreased to a value of the order of 0.57 to $1.02 \%$ after 10 days of fermentation. The acidification rates obtained are slightly normal and remain below the threshold of a strong acidifying potential $[4 ; 13]$.

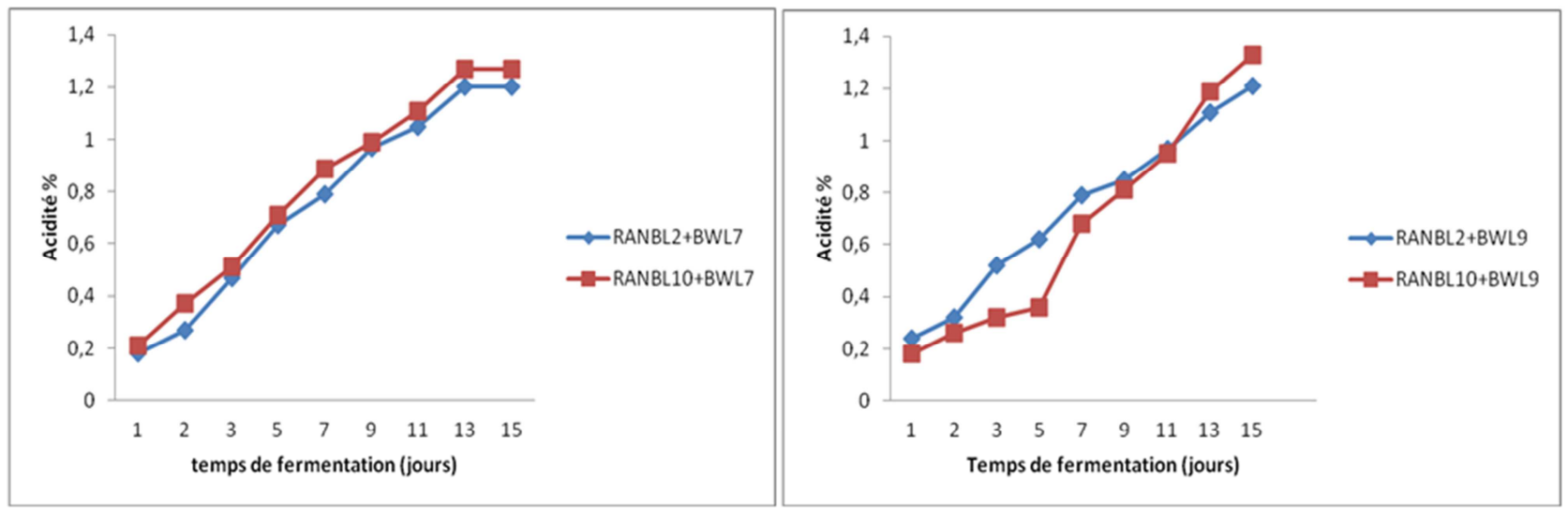

Figure 2. Evolution of acidity during the fermentation of the waste inoculated by a mixed culture.

\subsubsection{Influence of the Inoculum Rate}

We tested, with the mixed culture (lactic bacteria selected with a yeast) inoculation levels of $0.5 ; 1.0$; And $1.5 \mathrm{~g} / \mathrm{kg}$ of the lactic acid bacteria concentrate. These tests are carried out at ambient temperature and with an initial volume of $20 \%$ of molasses. The experimental results relating to these tests are shown in Table 4.

In all the tests carried out, it is noted that, starting from the proportion $1.0 \%$, the added inocula do not show any significant difference. The $\mathrm{pH}$ is stabilized after 15 days of fermentation. It is of the order of 4.07 to 3.97 and the microbial load reaches $17.108 \mathrm{cfu} / \mathrm{g}$ of finished product. The results of the fermentation tests show that the strains grown on turkey waste develop their activity at different rhythms [6].

The strains of lactic acid bacteria used are very active on mixed waste with at least $20 \%$ of molasses.

The proliferation of lactic acid bacteria is more rapid on wastes inoculated with a concentration of $1.0 \mathrm{~g} / \mathrm{kg}$ and $1.5 \mathrm{~g}$ $/ \mathrm{kg}$ whereas for wastes inoculated only with a concentration of $0.5 \mathrm{~g} / \mathrm{kg}$ at a shorter or longer time (10 to 15 days) is necessary for significant proliferation to be recorded.

Table 4. Effect of concentration of the inoculum on the course of the fermentation.

\begin{tabular}{|c|c|c|c|c|c|}
\hline Settings & & 0Days & 3Days & 07Days & 15Days \\
\hline \multirow{3}{*}{$0,5 \mathrm{~g} / \mathrm{kg}$} & $\mathrm{PH}$ & 6.71 & 5.11 & 4.21 & 4.23 \\
\hline & Lactic bacteria (ufc / g) & $2.10^{4}$ & $7.10^{7}$ & $12.10^{8}$ & $14.10^{8}$ \\
\hline & Odour & & - & - & - \\
\hline \multirow{3}{*}{$1.0 \mathrm{~g} / \mathrm{kg}$} & $\mathrm{PH}$ & 6.72 & 5.20 & 4.37 & 4.07 \\
\hline & Lactic bacteria (ufc / g) & $14.10^{5}$ & $8.10^{6}$ & $12.10^{7}$ & $2.10^{8}$ \\
\hline & Odour & - & - & - & - \\
\hline \multirow{4}{*}{$1.5 \mathrm{~g} / \mathrm{kg}$} & $\mathrm{PH}$ & 6.69 & 5.17 & 4.25 & 3.97 \\
\hline & Lactic bacteria (ufc / g) & $9.10^{5}$ & $11.10^{6}$ & $14.10^{8}$ & $17.10^{8}$ \\
\hline & Nematodes & 0 & 0 & 0 & 0 \\
\hline & Odour & - & - & - & - \\
\hline
\end{tabular}

\subsection{Physico-Chemical Analyzes}

The results of the composition of the fermented products are given in Table 5. These results show that this product has a balanced composition of nitrogen, phosphorus and organic matter which makes them an interesting ingredient to consider in soil fertilization even for 'animal feed.
The results show that the rate of dry matter and the ash after the biotransformation of the finished product obtained in the fermentation tests inoculated by a mixed culture are significantly high. This may be due to the difference in the initial raw material and the evaporation of the volatile compounds during mixing incubation and the effectiveness of the inoculum used [15]. 
Table 5. Physico-chemical and chemical analyzes of the finished product after waste biotransformation.

\begin{tabular}{lll}
\hline Paramètres & $\begin{array}{l}\text { Waste before } \\
\text { treatment }\end{array}$ & Product after fermentation \\
\hline PH & $6,72 \pm 0.23$ & $3,87 \pm 0.17$ \\
Titratable acidity (\%) & $0,27 \pm 0.14$ & $1,30 \pm 0.11$ \\
Total nitrogen (\%) & $3,43 \pm 0.23$ & $3,22 \pm 0.25$ \\
Phosphorus (\%) & $3,18 \pm 0.21$ & $4,32 \pm 0.23$ \\
Potassium (\%) & $4,12 \pm 0.53$ & $5,40 \pm 0.41$ \\
Dry matter (\%) & $27,02 \pm 0.34$ & $28,27 \pm 0.52$ \\
Ashes\% & $9.12 \pm 0.33$ & $10.79 \pm 0.21$ \\
Organic material (\%) & $39,86 \pm 0.28$ & $39.00 \pm 0.5$ \\
\hline
\end{tabular}

\subsection{Microbiological Analyzes}

The study of the profile of the microbial flora during fermentation of waste from slaughterhouses of red meat in cane molasses under similar conditions showed that the growth of lactic acid bacteria is favored during the first week of incubation with a Predominance of the selected strain. It should be noted that the agitation of barrel contents, especially during the first days, was of great importance for the success of biotransformation since it avoided the separation of waste and molasses due to a difference in their density.

The rise of the waste at the surface of the mixture, before the acidity reaches an inhibitory value, favors the activity of the flora of deterioration in the waste phase because of the low sugar concentration and consequently the low osmotic pressure. An increase in barrel content was observed during the first week of incubation. Indeed, the opening of the barrels after stirring was necessary to let the gases escape. This phenomenon of gas production during a biological fermentation is attributed to heterofermentation (production of acids).

Table 6. Microbiological analyzes of waste from slaughterhouses of red meat during fermentation tests.

\begin{tabular}{lllll}
\hline Microorganisms & Waste before treatment & 5 Days & 10 Days & 15 Days \\
\hline FMAT (ufc / g) & $2.10^{8}$ & $98.10^{6}$ & $83.10^{6}$ & $65.10^{5}$ \\
Fecal coliforms (cfu / g) & $3.10^{5}$ & $27.10^{3}$ & $11.10^{2}$ & 0 \\
Staphylococci (ufc / g) & $14.10^{4}$ & $7.10^{3}$ & 321 & 0 \\
Fecal Streptococci (cfu / g) & $21.10^{5}$ & $9.10^{3}$ & $2.10^{3}$ & 0 \\
Clostridia (ufc / g) & 57 & 27 & 0 & $2.10^{2}$ \\
Salmonella (ufc / g) & 0 & 0 & 0 & 0 \\
Lactic acid bacteria (cfu / g) & $13.10^{5}$ & $17.10^{5}$ & 0 & 0 \\
Yeasts (ufc / g) & $5.10^{4}$ & $11.10^{4}$ & $34.10^{6}$ & $8.10^{2}$ \\
\hline
\end{tabular}

\section{Discussion}

In fact, the total nitrogenous matter decreases during the period of biotransformation of the mixture, following the production of carbon dioxide and other components, in particular ammonia, resulting from the self-decomposition of waste under the effect of Flora of alteration and fermentation reactions [14].

The profiles of the microorganisms of hygienic interest were followed through the continuous count of the total aerobic mesophilic flora, our results show that the initial charge of the FMAT is of the order of $154.107 \mathrm{cfu} / \mathrm{g}$. After the fermentation process, the FMAT undergoes a considerable reduction to reach a value of $62.105 \mathrm{cfu} / \mathrm{g}$. It is clear from these results that the hygienic quality of the product has improved through the biotransformation process [7].

The flora indicative of fecal contamination assessed by the disappearance of fecal coliforms, Staphylococci, Salmonella and Clostridia are the consequences of lowering the $\mathrm{pH}$ to a level where most microorganisms are inhibited and probably producing inhibitory substances By fermentation [4].

The microflora profile of technological interest in slaughterhouse waste during biotransformation is reported in Table 3. The results show that lactic acid bacteria and yeasts have experienced a significant increase in their population in the medium. The population of lactic acid bacteria in the mixture grows gradually from an initial value of $13.105 \mathrm{cfu} /$ $\mathrm{g}$ to a high level of $81.107 \mathrm{cfu} / \mathrm{g}$ after 12 days of fermentation, indicating good growth Cells of this group of bacteria under our fermentation conditions $[1 ; 16]$.

\section{Conclusion}

The final product had an acceptable consistency as a result of biotransformation of slaughterhouse waste by fermentation with the use of microorganisms of biotechnological interest.

Moreover, the biological process applied showed that if the fermentation takes place under conditions of culture without addition of the selected microorganisms, the slaughterhouse waste will not develop into a good product. However, when the cultures are used in an appropriate combination with lactic acid bacteria, a better development of the organoleptic characteristics is obtained. This may suggest the important role of lactic bacteria combined with yeasts to give better results with respect to stability and change in the hygienic quality of the finished product. Testing of the fermentation mixture by mixed cultures may be involved in both preservation: the transformation and improvement of the organoleptic quality of the fermentation product [5;9]

These parameters must be taken into account in order to successfully produce the fermentation product and to obtain a nutrient-rich ingredient used in several fields [10].

\section{References}

[1] Benkerroum N, Ghouti Y, Sandine W E et tantaoui-Elaraki A. Methods to demostrate the bactericidal activity of bacteriocins, letters in applied microbiology, 1993, 17: 78-81. 
[2] Bossuyt, H., Six, J., and Hendrix, P. F. Rapid incorporation of carbon from fresh residues into newly formed stable microaggregates within earthworm casts. Eur. J. Soil Sci. 2004, 55: 393-399.

[3] Callewaert (R.), De Vuyst (L.) - Bacteriocin production with Lactobacillus amylovorus DCE 471 is improved and stabilized by fed-batch fermentation. - Appl. Environ. Microbiol., 2000, $66(2), 606-613$.

[4] Faid M, Achkari A et Elmarrakchi A. Transformation des déchets de poisson par voie biotechnologique. Cahier Agriculture. 1995; 4: 109-112.

[5] Gurpal S. Toor, Stefan Hunger, J. Derek Peak, J. Thomas Sims and Donald L. Sparks. Advances in the Characterization of Phosphorus in Organic Wastes: Environmental and Agronomic Applications. Advances in agronomy, science direct. 2006, 89 (1), 1-72.

[6] Gérard. M, POIGNANT. S. New techniques for recycling and recovery of household waste and ordinary industrial waste. Report 415. Parliamentary Office for the Evaluation of Scientific and Technological Options. June 1999. pp. 21-23.

[7] Han, K. S., Imm, J. Y., Oh, S., Jeon, W. M., Kim, S. H., 2002. Bacteriocin produced by Lactobacillus acidophilus ATCC 4356; characterization and purification. Food Sci. Biotechnol. $11,531-536$.

[8] Hammoumi A, Faid M, Zouiten A and Amarouch H. Biotransformation of fish waste by lactic fermentation. Microbiologie-aliments - nutrition. 1997; 15: 61-69.

[9] Labioui Hicham, RHAIT Mohammed, Abdelaziz MAQBOUL, Rabia Aoujdad, Driouich Abdelhak, OUHSSINE Mohammed. Contribution to the Characterization of Liquid Waste of Poultry Slaughter. Food Science and Quality Management, Vol.31, 2014.

[10] Labioui Hicham; RHAIT Mohammed; OUHSSINE Mohammed, Improvement of vegetation potato "Nicola" by slaughterhouses wastes treated by biological way. Journal of Biology, Agriculture and Healthcare (IISTE), 2013, 10-18.

[11] Lassen T. M., Lactic acid fermentation of fish offal and chicken by-products with different starter cultures. Agr. Sci. in Finland. 1994; 4: 19-26.

[12] Ouhssine M., Faid M., Courtois j et al. Lactic acid bacteria isolated from slaughterhouses wastes in morocco. International sugar journal (submitted) 1999.

[13] Ruf, A., Beck, L., Dreher, P., Hund-Rinke, K., Römbke, J. et Spelda, J. A biological classification concept for the assessment of soil quality: "biological soil classification scheme" (BBSK). Agriculture Ecosystems and Environment, 2004, 98: 263-271.

[14] Reuveni, R., Raviv, M., Krasnovsky, A., Freiman, L., Medina, S., Bar, A., et Orion, D. 2002. Compost induces protection against Fusarium oxysporum in sweet basil. Crop Protection, 21: 583-587.

[15] Parente E., Ricciardi A., Addario G. Influence of $\mathrm{pH}$ on growth and bacteriocin production by Lactococcus lactis subsp. lactis 140NWC during batch fermentation. - Appl. Microbiol. Biotechnol. 1994; 41: 388-394.

[16] Zahar M., Benkerroum N., Guerouali et al. Effect of temperature, anaerobiosis, stirring and salt addition on natural fermentation silage of sardine and sardine wastes in sugarcane molasses. Bioresource Technol. 2002; 82 (2): 171-176. 